\title{
Effects of Mobilization with Movement (MWM) in Shoulder Impingement Syndrome Patients on Acromiohumeral Distance using Ultrasonography
}

\author{
Dabholkar Ajit and Shetty Shika
}

\begin{abstract}
Aim: To study the effect of MWM on acromiohumeral distance, pain and disability in patients with Shoulder Impingement Syndrome. Method: Fifteen subjects with shoulder impingement syndrome were selected. Participants were treated with MWM posterolateral glide for shoulder for 6 sessions. The main outcome measures include dultrasonographic measurement of the acromiohumeral distance, VAS, SPADI and DASH scale. Results: There were extremely significant changes seen in the acromiohumeral distance in patients with impingement pre and post MWM treatment with $\mathrm{p}$ value of $<0.0001$. Pain and disability also showed extremely significant changes with a $\mathrm{p}$ value of $<0.0001$. Conclusion: The study concludes that MWM is effective in increasing the acromiohumeral distance and in reducing pain and disability in patients with shoulder impingement syndrome.
\end{abstract}

Dabholkar Ajit, Professor and Head of Sports PT,D.Y.PatilSchool of Physiotherapy,Nerul, Navi Mumbai, India. Email:ajitdabholkar78@yahoo.co.in

Shetty Shika,M.P.T Student, D.Y.Patil School of Physiotherapy, Nerul, Navi Mumbai, India.

Email:shika_shetty@hotmail.com
Key Words: Mulligan, Posterolateral glide, SPADI, DASH, Pain, Disability

DOI: $10.18376 / j e s p / 2016 / v 12 / \mathrm{i} 2 / 111262$

\section{Introduction}

Shoulder disorders are among the most common of all peripheral joint complaints (Chard et al,1991; Lo et al,1990). Shoulder Impingement Syndrome (SIS) is defined as the mechanical entrapment of the rotator cuff (mainly the supraspinatus tendon) or the subacromial bursa in the subacromial space between the humeral head and the acromion or coracohumeral ligament (Ellenbecker. et al,2010; Cools et al,2008).It is characterized by shoulder pain that is exacerbated by arm elevation or overhead activities(Ludewig et al,2000; Lukasiewicz et al,1999). The etiology of SIS is multifactorial. Two main contributing factors are: (1) Narrowing of the subacromial space (2) Enlargement of the subacromial tissues (bursae /tendons)(Cholewinski et al,2008; Wang et al,2005).The subacromial space was quantified by the acromiohumeral distance (Cholewinski et al,2008).The subacromial space or acromiohumeral distance could be measured using ultrasound which was found to be a technique that is non-invasive, radiation free and has high validity when compared with others (Azzoni et al,2004).More extensively studied is the subacromial space at the anterior outlet via the acromiohumeral distance measure on ultrasound images with the majority of studies reporting a smaller AHD in those with subacromial impingement syndrome (Bhatt et al,2013). Many factors have been proposed as contributors to the development of shoulder impingement syndrome (Michener et al, 2003).Mechanisms include intrinsic changes in the supraspinatus tendon and extrinsically 


\section{Journal of Exercise Science \& Physiotherapy, Vol. 12, No. 2, 2016 ISSN: 0973-2020 (Print) \\ ISSN: 2454-6089 (Online)}

the direct mechanical compression of the supraspinatus tendon in the subacromial space (Neer ,1983). Characterizing supraspinatus tendon dimension and the tendon thickness in proportion to the subacromial space will aid our understanding of the mechanism of this (Michener. et al,2015).Ultrasonography is a useful technique for imaging a large variety of musculoskeletal disorders(Bhatt et al,2013).Studies suggest that shoulder ultrasound performed in patients with Shoulder Impingement Syndrome visually showed decreased size of subacromial space and rotator cuff thickness (When compared to persons not affected by this condition) (Cholewinski et al,2008).Conservative treatment of the shoulder impingement syndrome consists of a wide range of procedures, manual therapy being one of them (Olivera et al, 2012).MWM is a manual therapy technique in which a manual force, usually in the form of a joint glide is applied to a motion segment and sustained while a previously impaired action (e.g.painful abduction movement) is performed (Vicenzino et al,2007). If the active movement performed is pain free, the orientation of the glide will be considered adequate (Mulligan et al,2014). The principles for this type of joint mobilization are based on analyzing and correcting any minor positional fault in the patient, which according to the MWM theory occurs due to the various soft and/or bony tissue lesions in/around the joint (Mulligan et al,2014).The purpose of this study was to investigate the effects of MWM on AHD, pain and disability in patients with Shoulder Impingement Syndrome.

\section{Methods}

It's a Quasi experimental type of study. All the fifteen $(n=15)$ subjects were selected from the Physiotherapy OPD at Dr.D.Y.Patil Hospital and Research Center, Navi Mumbai. The study duration was 1 year. Patients diagnosed with Shoulder Impingement Syndrome were selected. Inclusion criteria: Subjects selected for the study were included on the basis of those showing Positive Hawkins Kennedy test, Positive Neer's Impingement test and Positive Horizontal Adduction test. Exclusion criteria: Those having complete rotator cuff tear, H/O active shoulder dislocation/subluxation or fracture, H/O Shoulder surgery and Adhesive capsulitis. Materials used were Ultrasound Machine (Mindray) with 7$\mathrm{MHz}$ linear tranducer used for measuring AHD and Supraspinatus tendon thickness, Shoulder Pain and Disability Index (SPADI), Disabilities of Arm, Shoulder and Hand (DASH) and Stool.

\section{Procedure}

Approval for the study was gained from the Institutional Ethics Committee. All subjects were explained the purpose of the study and written consent was taken from all of them prior to assessment. Patients meeting the inclusion criteria were selected for the study. Proforma was filled by interviewing the subjects which included information about their gender, age, height, weight, location and duration of symptoms, previous history of shoulder pain, and pain intensity using $10 \mathrm{~cm}$ Visual Analogue Scale. Pre evaluation was done followed by treatment protocol of MWM for 6 sessions with 24 hours between sessions after which post evaluation was done. Pre and Post Evaluation were done using following outcome measures:

- Functional status of patients were assessed with SPADI and DASH scale (Roach et al,1991; Hudak et al,1996).

- USG measurements of AHD and SST. 


\section{Journal of Exercise Science \& Physiotherapy, Vol. 12, No. 2, 2016 ISSN: 0973-2020 (Print) \\ ISSN: 2454-6089 (Online)}

The intervention included MWM posterolateral glide for shoulder. Patient seated at the edge of a chair. Patients arm should be in external rotation while performing abduction. The therapist stands on the lateral side of the unaffected shoulder. Therapist stabilizes scapula with one hand. Thenar eminence of the other hand is placed medial to the head of humerus. Therapist glides the humeral head in postero-lateral-inferior direction with thenar eminence. Patient performs the offending movement while the glide is sustained. This movement should now become pain-free. Passive overpressure can be given by the patient at the end of new available range using his other hand. The hand of the therapist should also move along with the movement in order to sustain the glide along the treatment plane. Allow upward rotation of the scapula as the patient moves his shoulder (Mulliganet al,2014).

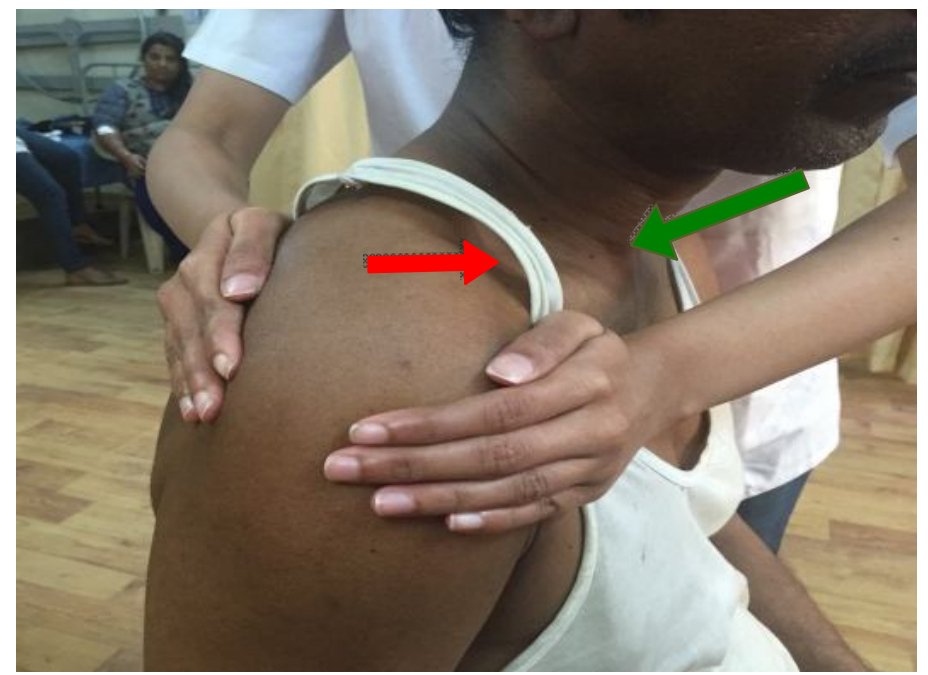

Figure 1. MWM Posterolateral glide for Shoulder

MWM - 10 repetitions daily, $30 \mathrm{sec}$ rest period between sets, 6 sessions with 24 hours between sessions.USG measurements of each participant, AHD and SST were scanned using a Mindray ultrasound machine in conjunction with a 7-MHz linear transducer.

\section{AHD: Acromio-humeral distance}

The AHD measurement was taken with the participant in sitting position. His/her head was in neutral position, arm in $0^{\circ}$ flexion, elbow were in full extension and forearm in neutral position. The transducer was placed on the lateral surface of the shoulder along the longitudinal view and was measured from the infero-lateral edge of acromion to the apex of the greater tubercle (Cholewinski et al,2008). 
Journal of Exercise Science \& Physiotherapy, Vol. 12, No. 2, 2016

ISSN: 0973-2020 (Print)

ISSN: 2454-6089 (Online)

Figure 2. Acromiohumeral distance SST: Supraspinatus tendon thickness

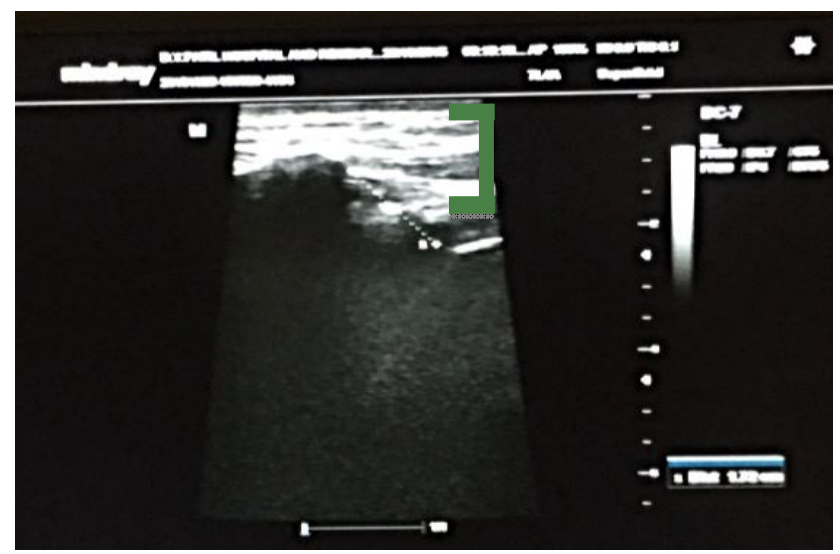

SST was taken with the patient in sitting position. His/her head was in neutral position, with the palmar side of the hand on the superior aspect of the iliac crest, with elbow flexed and directed posteriorly towards the midline. The SST was scanned in transverse view and the thickness of the tendon was measured at $30 \mathrm{~mm}$ lateral to the long head of biceps tendon (Cholewinski et al,2008; Wallny et al,1999).

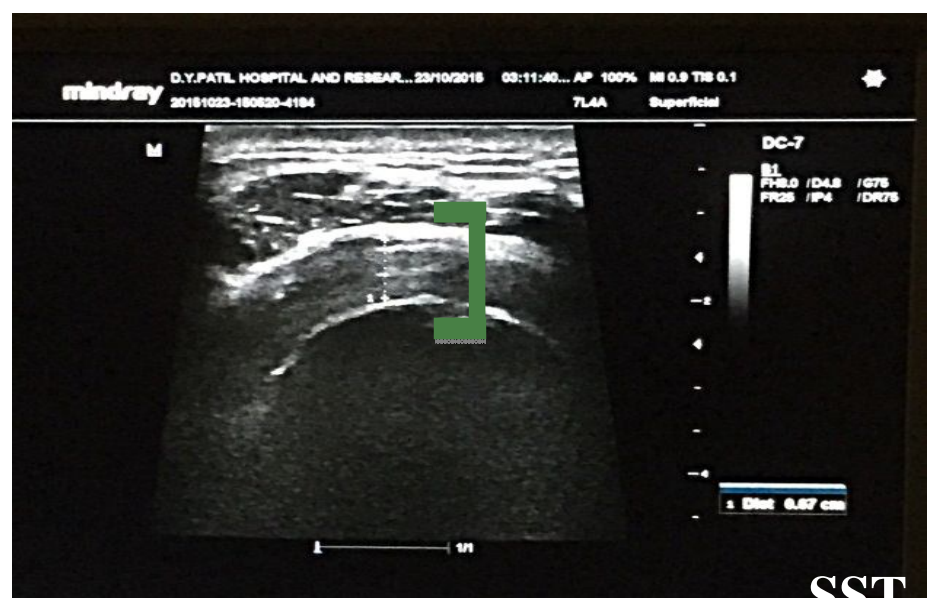

Figure 3. Supraspinatus thickness

The data was statistically analyzed by Wilcoxon Test. 


\section{Results}

All subjects completed the intervention program study. The demographic variables of the subjects were as follows:

Table 1. Demographic Variables

\begin{tabular}{lcc}
\hline Variables & Mean & Standard Deviation \\
\hline Age & 53.86 & 8.84 \\
Duration of pain & 2.86 & 1.99 \\
VAS & 6.52 & 1.45 \\
M:F & $7: 8$ & \\
\hline
\end{tabular}

Table 2. Demographic Data

\begin{tabular}{|c|c|c|c|c|}
\hline \multirow[t]{2}{*}{ VARIABLES } & \multicolumn{2}{|c|}{ Mean+/-SD } & \multirow[t]{2}{*}{ P value } & \multirow[t]{2}{*}{ Significance } \\
\hline & Pre & Post & & \\
\hline AHD & $\begin{array}{l}0.92+/- \\
0.16\end{array}$ & $\begin{array}{l}1.25+/- \\
0.16\end{array}$ & $<0.0001 * * *$ & ES \\
\hline SST & $\begin{array}{l}0.61+/- \\
0.08\end{array}$ & $\begin{array}{l}0.68+/- \\
0.07\end{array}$ & $<0.0039 * *$ & VS \\
\hline SPADI Scale & $\begin{array}{l}46.96+/- \\
9.64\end{array}$ & $\begin{array}{l}9.73+/- \\
3.34\end{array}$ & $<0.0001 * * *$ & ES \\
\hline DASH Scale & $\begin{array}{l}51.71+/- \\
7.84\end{array}$ & $\begin{array}{l}28.63+/- \\
7.20\end{array}$ & $<0.0001 * * *$ & $\mathrm{ES}$ \\
\hline $\begin{array}{l}\text { VAS-Hawkins Kennedy } \\
\text { Test }\end{array}$ & $\begin{array}{l}6.72+/- \\
1.53\end{array}$ & $\begin{array}{l}0.48+/- \\
0.43\end{array}$ & $<0.0001 * * *$ & ES \\
\hline VAS-Neers & $\begin{array}{l}6.75+/- \\
1.55\end{array}$ & $0.38+/-$ & $<0.0001 * * *$ & ES \\
\hline Impingement Test & 1.55 & 0.37 & & \\
\hline $\begin{array}{l}\text { VAS-Horizontal } \\
\text { Adduction Test }\end{array}$ & $\begin{array}{l}6.06+/- \\
1.73\end{array}$ & $\begin{array}{l}0.32+/- \\
0.38\end{array}$ & $<0.0001 * * *$ & ES \\
\hline $\begin{array}{l}\text { Internal Rotation } \\
\text { Strength }\end{array}$ & $\begin{array}{l}2.40+/- \\
1.12\end{array}$ & $\begin{array}{l}3.33+/- \\
1.23\end{array}$ & $<0.0674$ & NS \\
\hline $\begin{array}{l}\text { External Rotation } \\
\text { Strength }\end{array}$ & $\begin{array}{l}0.93+/- \\
1.03\end{array}$ & $\begin{array}{l}2.53+/- \\
0.91\end{array}$ & $\begin{array}{c}< \\
0.0010^{* * *}\end{array}$ & $\mathrm{ES}$ \\
\hline
\end{tabular}

\section{Discussion}

In a study by Hio-Teng Leong et al 2012, the subacromial space was quantified by the AHD. The etiology of SIS is multifactorial, one of them being narrowing of subacromial space (Cholewinski et al,2008; Wang et al,2005). A study by Jerzy et al, 2008 suggested that shoulder ultrasound performed in patients with symptoms of SIS usually showed decreased size of subacromial space. Ultrasonographic assessment of humeral head elevation, measured as the AGT distance (the distance between the infero-lateral edge of acromion and the apex of the greater tuberosity of humerus), proved to be useful in establishing the diagnosis of the subacromial impingement syndrome of the 


\section{Journal of Exercise Science \& Physiotherapy, Vol. 12, No. 2, 2016 ISSN: 0973-2020 (Print) \\ ISSN: 2454-6089 (Online)}

shoulder(Neer,1983). Our study concludes that Mulligan MWM posterolateral glide helps in correcting positional fault by repositioning the joint causing it to track normally, (Hing,2007) thus increasing AHD post Mulligan treatment session. An extrinsic mechanism is theoretically supported which states direct mechanical compression; measures of direct tendon compression during arm elevation are needed to verify this mechanism. Surgical intervention to increase subacromial space may be considered if tendon compression can be verified (Lori et al,2015). Statistically significant difference in rotator cuff thickness between the affected and unaffected joints found within the study group results from the decrease in thickness of the rotator cuff during the development of SIS, which was observed by some authors (Seibold et al,1999; Wiener et al,1993).Our study concludes that the supraspinatus tendon compression is relieved because of increase in the AHD pre to post Mulligan MWM posterolateral glide treatment ,because of which there is slight increase in the supraspinatus tendon thickness. A study done by Aimie et al,2008 have shown that MWM with supervised exercise showed the highest percentage of change in decreasing pain and improving functions from pre to post treatment. Since the SPADI function test is based on shoulder pain with functional activities thus, interventions resulting in pain reduction would also result in an improved SPADI score. One of the case report done by Lucy et al, 2006 concludes that MWM may be an effective treatment intervention for patients with impingement which has an improvement in SPADI scores, which is proved in our study. The Disabilities of the Arm, Shoulder, and Hand questionnaire (DASH), is the most widespread and best-tested and characterized instrument for shoulder assessment (Angst et al,2011).Also, we have found that MWM helps in decreasing pain and improving functions from pre to post Mulligan MWM posterolateral glide treatment, therefore improving DASH scores. A study done by Aimie et al, suggested that the MWM group had a higher percentage of change from pre to post treatment on all three pain measures (VAS, Neer, Hawkins Kennedy) (Aimieet al,2008).It is likely that the movement produced by MWM techniques resulted in pain reduction through activation of mechanoreceptors inhibiting nociceptive stimuli through the gate control mechanism or through facilitation of synovial fluid nutrition (Melzack et al,1965; Wall 1978; Threlkeld1992).MWM also has an hypoalgesic and sympathetic nervous system (SNS) excitation effect (Wallny et al,1999). Therefore in our study we found that because of pain reduction the VAS scales have improved post Mulligan MWM posterolateral glide treatment improving patients functions.

\section{Conclusion}

Thus are study concludes that MWM is effective in increasing the acromiohumeral distance in patients with shoulder impingement syndromeand it is also effective in reducing pain and disability thereby improving the patients functions.

\section{Acknowledgements}

Sincere thanks to all the participants of the study and the HOD of the Radiology dept Dr. Madan Manmohan and Senior Resident Dr.Shipra Singh.

\section{References}

Aimie F. Kachingwe, EdD, Beth Phillips, et al.(2008). Comparison of Manual TherapyTechniques with Therapeutic Exercise in the Treatment of Shoulder Impingement: A Randomized Controlled Pilot Clinical Trial.J Man ManipTher.16(4):238-247. 


\section{Journal of Exercise Science \& Physiotherapy, Vol. 12, No. 2, 2016}

ISSN: 0973-2020 (Print)

ISSN: 2454-6089 (Online)

Angst.F, Schwyzer.HK, Aeschlimann.A,et al.(2011).Measures of Adult ShoulderFunction.Arthritis Care \& Research.174-188.

Azzoni R, Cabiza P, Parrini M.(2004). Sonographic evaluation of subacromial space.Ultrasonics.42:683-687.

Bhatt .S, Bhargav S.K.(2013).Dynamic musculoskeletal sonography.

JIMSA.26(1):21-24

Chard MD, Hazleman BL, King RH, Reiss BB.(1991). Shoulder disorders in the elderly: a community survey. Arthritis Rheum. 34:766-769.

Cholewinski JJ, Kusz DJ, Wojciechowski P, et al.(2008). Ultrasound measurement of rotator cuff thickness and acromio-humeral distance in the diagnosis of subacromial impingement syndrome of the shoulder.Knee Surg Sports Traumatol Arthrosc. 16:408-414.

Cools AM, Cambier D, Witvrouw EE. (2008).Screening the athlete's shoulder for impingement symptoms: a clinical reasoning algorithm for early detection of shoulder pathology. Br J Sports Med. 42:628-635.

DeSantis.L; Hasson.S et al.(2006).Use of Mobilization with Movement in the Treatment of a Patient with Subacromial Impingement: A Case Report.J Man ManipTher .77-87.

Ellenbecker TS, Cools A.(2010).Rehabilitation of shoulder impingement syndrome and rotator cuff injuries: an evidence-based review. $\mathrm{Br} \quad \mathrm{J}$ SportsMed. 44:319-327.

Hing.W.(2008).Mulligan's mobilisation with movement: a review of the tenets and prescription of MWMs.

NewZealand Journal of Physiotherapy.36(3):144-164

Hudak P, Amadio PC, Bombardier C, and the Upper Extremity Collaborative Group.(1996). Development of an Upper Extremity Outcome Measures: The DASH(Disabilities of the Arm, Shoulder, and Hand). American Journal of Industrial Medicine .29:602-608.

Leong HT, Tsui S, Ying M et al .(2012) .Ultrasound measurements on acromiohumeral distance and supraspinatus tendon thickness: test-retest reliability and correlations with shoulder rotational strengths. J Sci Med Sport .15:284-291.

Lo YP, Hsu YCS, Chan KM.(1990). Epidemiology of shoulder impingement in upper arm sports events. Br J Sports Med. 24:173-177.

Ludewig PM, Cook TM.(2000). Alterations in shoulder kinematics and associated muscle activity in people with symptoms of shoulder impingement. PhysTher.80:276-91.

Lukasiewicz AC, McClure P, Michener L, Pratt N, Sennett B. (1999).Comparison of 3-dimensional scapular position and orientation between subjects with and without shoulder impingement. J Orthop Sports PhysTher.29:574-83.

Melzack R, Wall PD.(1965). Pain mechanisms: A new theory. Science.150:971979.

Michener LA, McClure PW, KardunaAR. (2003).Anatomical and biomechanical mechanisms of subacromial impingement syndrome. Clin Biomech. 18:369-379.

Michener.L ,Sevgi S, Yesilyaprak.S et al.(2015). Supraspinatus tendon and subacromial space parameters measured on ultrasonographic imaging in 
subacromial impingement syndrome. Knee Surg Sports Traumatol Arthrosc.363-369.

Mulligan .B , Kumar .D. (2014).Manual of Mulligan Concept,Capri Institute of Manual Therapy, Chapter 8 ,Shoulder Joint,Page no 148.

NeerCS .(1983). Impingement lesions. Clin Orthop Relat Res. 3(173):70-77.

Olivera C. Djordjevic, MD, Vukicevic.D, MD, Katunac.L,et al.(2012) .Mobilization with movement and kinesiotaping compared with a supervised exercise program for painful shoulder: results of a clinical trial. Journal of Manipulative And Physiological Therapeutics.35(6):45463

Roach KE, Budiman-Mak E, Songsiridej N, Lertratanakul Y.(1991) Development of a shoulder pain and disability index. Arthritis Care Res.4(4):143-9.

Seibold CJ, Mallisee TA, Erickson SJ, Boynton MD, Raasch WG, Timins ME (1999) Rotator Cuff: Evaluation with US and MR Imaging. Radiographics .19:685-705.8.

Threlkeld AJ. (1992).The effects of manual therapy on connective tissue. Phys Ther.72: 893-902.

Vicenzino.B, Paungmali.A and Teys.P.(2007). Mulligan's mobilization-withmovement, positional faults and pain relief: Current concepts from a critical review of literature.Manual Therapy.12 (2): 98-108.

Wall PD.(1978). The gate control theory of pain mechanisms: An reexamination and a re-statement. Brain.101:1-18.

Wallny T, Wagner UA, Prange S, et al.(1999). Evaluation of chronic tears of the rotator cuff by ultrasound.J Bone Joint Surg .81:675-678.

Wang HK, Lin JJ, Pan SL, et al.(2005).Sonographic evaluations in elite college baseball athletes.Scand J Med Sci Sports. 15:29-35.

Wiener SN, Seitz WH Jr.(1993).Sonography of the shoulder in patients with tears of the rotator cuff: accuracy and value for selecting surgical options. AJR Am J Roentgenol.160:103-107.

Conflict of Interest: None Declared 